\title{
Job satisfaction of South African registered dietitians
}

\author{
Visser J, MNutr, Senior Lecturer and Postgraduate Coordinator; Mackenzie A, MNutr, Postgraduate Student \\ Division of Human Nutrition, Stellenbosch University and Tygerberg Academic Hospital \\ Marais D, PhD, Postgraduate Coordinator \\ Division of Human Nutrition, Stellenbosch University and Tygerberg Academic Hospital \\ Population Health, Division of Applied Health Sciences, University of Aberdeen, Aberdeen, Scotland, UK \\ Correspondence to: Janicke Visser, e-mail: jconrad@sun.ac.za \\ Keywords: job satisfaction, South African registered dietitians
}

\section{Abstract}

Objectives: The aim of this study was to determine the overall level of job satisfaction among South African registered dietitians and possible relationships between the influencing factors.

Design: The design was a cross-sectional descriptive study.

Setting and subjects: A national survey was carried out among all dietitians registered with the Health Professions Council of South Africa, excluding community service dietitians.

Outcome measures: A two-part, self-administered, adapted job satisfaction survey questionnaire was used. Demographic data were collected. The questionnaire covered nine themes pertaining to job satisfaction: salary, promotion, knowledge and skills, professional colleagues, being a member of the multidisciplinary team, communication, the work environment, rewards of the job and nature of the work.

Results: A final response rate of $22.5 \%(n=340)$ was obtained. South African registered dietitians were only slightly satisfied $(65.7 \%)$ with their current employment. There was no significant difference $(p$-value $=0.291)$ pertaining to overall job satisfaction between those working and living overseas and those working and living in South Africa. Primarily, lower levels of satisfaction were observed to be due to poor salaries, lack of promotion opportunities and a poor perception of professional image. Significant positive correlations were found between age ( $p$-value $=0.036)$, professional experience ( $p$-value $=0.035)$, area of expertise ( $p$-value $=0.001)$, hours of work $(p$-value $=0.021)$ and location of work (p-value $=0.00001)$.

Conclusion: Although overall job satisfaction scores indicated that South African registered dietitians are only slightly satisfied with their employment, registered dietitians reported that they love the nature of the work and what they do, tending towards confirmation of career satisfaction. Recommendations include re-evaluation of registered dietitian salary scales, career pathing with promotion opportunities, boosting the professional image and expanding the teaching of nondietetic skills to dietetic undergraduates.

(P) Peer reviewed. (Submitted: 2012-01-25. Accepted: 2012-07-01.) ๑ SAJCN

S Afr J Clin Nutr 2012;25(3):112-119

\section{Introduction}

Job satisfaction is defined as the extent to which one is generally fulfilled by or the pleasure derived from one's current job and working conditions. ${ }^{1,2}$ Personal, interpersonal and organisational factors have been shown to be associated with job satisfaction.

Measures of these factors include the following:

- Demographic variables (age, gender, family and marital status, level of education, professional expertise and professional experience)

- Variables of the work task (autonomy, workload and work task diversity and achievement in the job)

- Variables that form part of the work environment (salary, rewards, benefits, contracts, hours of work, physical environment, urban- vs. rural-based work, working in the public vs. the private sector, and professional development and professional status)., ${ }^{3,4}$

Key aspects that have been identified in contributing to job satisfaction are job recognition, level of salary, opportunities for promotion and achievement of personal goals. ${ }^{5-9}$ Job satisfaction is important for both employers and employees. In the case of healthcare professionals, it is also in the interests of the patient or client and the multidisciplinary teams with which the healthcare professional engages. ${ }^{7,10}$ Low job satisfaction can be a reason for individuals to leave a profession or even their area or country of residence in search of greater job satisfaction. ${ }^{11-13}$

However, job satisfaction is subjective and is based on individuals' attitudes and expectations, together with the impact of different 
variables that can act either independently, or in combination, to influence the overall attitude. This complexity and variety of variables, as well as the unknown or undefined variables, makes the measurement of job satisfaction very difficult. ${ }^{14,15}$ Van Saane et al clearly state that there is no "gold standard" for the measurement of job satisfaction, especially because there are no standardised variables..$^{16} \mathrm{~A}$ variety of methods and tools have been used in past studies in an attempt to best measure job satisfaction. Literature quotes the use of focus groups, ${ }^{12}$ individual interviews, either directly ${ }^{17-19}$ or telephonically ${ }^{20}$ and self-administered questionnaires; the method most widely used..$^{21-32}$

Most studies report a slight to moderate level of job satisfaction among healthcare professionals. Most of the available evidence on job satisfaction within the medical field has focused on nurses and doctors. ${ }^{21,22,24-29,33}$ Few studies were conducted among the allied health professions, ${ }^{7,8,12,34-37}$ and even fewer among registered dietitians. .,6,9,38,39 $^{5}$ Studies on registered dietitians were carried out in the 1980s to early 1990s. s,6,38,40 $^{5}$ There was only one more recent study, in 2006. ${ }^{9}$ Most of the research stems from the USA. In summary, the American strong research base demonstrated that registered dietitians were generally satisfied with their work when they received recognition of their expertise from the public, ${ }^{39}$ and recognition of their contribution within multidisciplinary professional healthcare teams. ${ }^{41}$ Yet, strong trends included low levels of satisfaction due to poor salaries, $5,6,9,39$ insufficient opportunities for career growth, ${ }^{5,6,9}$ lack of respect from healthcare professionals, ${ }^{39}$ competition from dietetic colleagues that created professional isolation, ${ }^{39}$ difficulty in maintaining professional development, ${ }^{42}$ and a negative public perception (the "food police") of registered dietitians. $^{39}$

This study took into consideration the current low levels of job satisfaction that were found among healthcare professionals throughout the world and the paucity of local evidence in this regard. It investigated the level of job satisfaction among South African registered dietitians and endeavoured to determine what influences job satisfaction in this context.

\section{Method}

This cross-sectional descriptive study included all 1509 dietitians who were registered with the Health Professions Council of South Africa (HPCSA) for the year ending 2007 (excluding community service dietitians, $n=193$ ). The latter were excluded from this national survey because they are in temporary posts designated by the Department of Health (DOH) for a period of one year only.

Because of the wide geographic distribution of the sample across the country and overseas, a self-administered questionnaire was deemed to be the most practical tool for data collection. The questionnaire was piloted for content validity and appropriate changes were made to it. The questionnaire consisted of two sections that collected data pertaining to demographics (23 questions) and level of job satisfaction. The Job Satisfaction Survey (JSS) questionnaire ${ }^{43}$ was selected as the most suitable from a range of available job satisfaction questionnaires. It was adapted to contain questions that were more relevant or appropriate to registered dietitians. The adapted JSS contained nine themes and 36 questions (four questions per theme). Respondents were asked to rate their responses using an even 6-point Likert scale, from "disagree very much" to "agree very much". These themes included salary, promotion opportunities, professional development, relationships with fellow dietitians, recognition from other healthcare professionals, the rewards of the job, the nature of the work, the working environment and communication. The respondents were asked where they envisaged themselves in five years' time in relation to their current employment. A covering letter was sent out either by e-mail (the preferred method, where available) or by post. It contained an introduction to and explanation of the purpose of the research, proof of ethics approval by Stellenbosch University (N07/09/212), the information required from the respondent, the time required to complete and return the questionnaire and assurance of the anonymity and confidentiality of all respondents.

The 2007 HPCSA database was made available by the Division of Human Nutrition, Stellenbosch University, which purchased and obtained permission to use the database. As the HPCSA database contained only postal addresses, the Association for Dietetics in South Africa (ADSA) was contacted to make use of its database which also included e-mail addresses for members. In the interests of reduction of postal and paper costs and independence from possible delays within the postal system, e-mail was the preferred method of contact. ADSA members, with corresponding e-mail addresses, were extracted from the HPCSA list, using the HPCSA registration number for identification and contacted via e-mail $(53.7 \%, \mathrm{n}=$ 811). All remaining registered dietitians on the HPCSA list, excluding community service dietitians, but including non-ADSA members and ADSA members without a recorded e-mail address, were contacted by post $(46.3 \%, \mathrm{n}=698)$. Postal distributions included self-addressed envelopes with pre-paid postage to encourage participation and to ensure that respondents did not have to incur any costs through participating in the project. Data collection, including distribution of cover letters and questionnaires, took place at the beginning of 2008. In an effort to increase the response rate, a reminder was posted in the ADSA monthly newsletter, six weeks after dissemination of the initial e-mail, while postal reminders were only sent to non-responders who had received the postal survey. Although various forums, including ADSA branch meetings, were used to encourage dietitians to participate via e-mail or post, questionnaires were not handed out at these sessions to enable control of the responses (to safeguard against dietitians completing more than one questionnaire). To ensure that the respondents were not overburdened, as healthcare professionals are often bombarded with various e-mails and notices, the researchers determined that those who wanted to participate would do so after two notices, including the one reminder. Both the initial and the reminder batches requested that completed questionnaires should be returned within a month of the date that they were received.

The data were captured in an Excel $^{\circledR}$ worksheet and analysed using Statistica ${ }^{\circledR}$ 8.0. The response rates and frequencies for the demographic data were calculated. Mean overall scores for the nine themes and overall job satisfaction using the adapted JSS were calculated and categorised according to the JSS categories of very low satisfaction (0-17\%), moderately low satisfaction (17.1-33\%), 
slightly low satisfaction (33.1-50\%), slightly satisfied (50.1-66\%), moderately satisfied (66.1-83\%) and very satisfied (83.1-100\%). The analysis of variance (ANOVA) test was used to determine the difference between the levels of the nominal variables. In cases where the data had a normal distribution, the ANOVA F-test was employed, whereas for data not normally distributed, the Mann-Whitney $U$ test to assess two groups, or the Kruskal-Wallis test to assess three or more groups, was used. A regression and correlation analysis was applied to compare continuous variables. Where variables were not normally distributed, the Spearman rank correlation analysis was used. Statistical significance was set at a p-value of less than 0.05 .

\section{Results}

The e-mail survey provided 196 responses (a response rate of $24.3 \%$ ). One hundred and forty-four respondents chose the postal method (a response rate of $20.6 \%$ ). This made up a final representative sample of 340 responses from a possible 1509 registered with the HPCSA (an overall response rate of $22.5 \%$ ). The reminder notice that was sent out increased the overall response rate for both methods by $6.3 \%(n=96)$ from $16.2 \%(n=244)$ to $22.5 \%(n=340)$.

\section{Demographic data}

The representative sample of 340 registered dietitians was predominantly female (97.5\%), married (59.1\%) and without children $(53 \%)$, with a mean age of 33.3 years (standard deviation 8.3 ) (Table I). Half $(50 \%)$ of the respondents were Afrikaans-speaking. The majority lived and worked in South Africa (92.6\%). Almost half $(49.7 \%)$ had a postgraduate qualification (a diploma or honours degree). Only nine per cent had a master's degree and 3.5\%, a doctorate degree. The majority of the respondents $(72.6 \%)$ were in full-time employment and worked in urban or suburban areas (83.5\%). Forty per cent worked for the $\mathrm{DOH}, 37.1 \%$ worked in the private sector and the remaining $22.9 \%$ in the fields of education, research, industry and food service. Half of the respondents had been practicing dietetics for $0-5$ years (45.7\%) and had been in their current job for only $0-5$ years (66.2\%). The average salary level was calculated to be between R92 000 and R141 000 per annum, with only $4.1 \%$ earning > R392 000 per annum. Only 51.7\% reported having a fixed contract for their current position. Although dietetic specialisation per se is not currently allowed by the HPCSA , almost half $(49.1 \%, n=167)$ of the dietitians considered themselves to have

Table I: Demographic characteristics of the sample of South African registered dietitians $(n=340)$

\begin{tabular}{|c|c|c|c|c|c|}
\hline $\begin{array}{l}\text { Demographic } \\
\text { characteritstics }\end{array}$ & Frequency \% (n) & $\begin{array}{l}\text { Demographic } \\
\text { characteritstics }\end{array}$ & Frequency $\%$ (n) & $\begin{array}{l}\text { Demographic } \\
\text { characteritstics }\end{array}$ & Frequency \% (n) \\
\hline \multicolumn{2}{|l|}{ Age } & \multicolumn{2}{|l|}{ Level of qualification } & \multicolumn{2}{|l|}{ Salary (cont.) } \\
\hline $20-29$ & $39.4(134)$ & Bachelor's & 37.7 (128) & R63 000-R91 999 & $14.4(49)$ \\
\hline $30-39$ & $42.4(144)$ & Postgraduate diploma & $25.6(87)$ & R92 000-R141 999 & $31.5(107)$ \\
\hline $40-49$ & $10.6(36)$ & Honour's & $24.1(82)$ & R142 000-R211999 & $21.5(73)$ \\
\hline $50-59$ & $7.1(24)$ & Master's & $9.1(32)$ & R212 000-R391 999 & $17.4(59)$ \\
\hline $60-69$ & $0.5(2)$ & Doctorate & $3.5(12)$ & $>$ R392 000 & $4.1(14)$ \\
\hline \multicolumn{2}{|l|}{ Gender } & Area of expertise: Yes & 49.1 (167) & \multicolumn{2}{|l|}{ Years in current job } \\
\hline Male & $2.1(7)$ & Allergies & $3.8(13)$ & $0-5$ & $66.2(225)$ \\
\hline Female & $97.5(333)$ & Diabetes & $16.8(57)$ & $5-10$ & $16.0(54)$ \\
\hline \multicolumn{2}{|l|}{ Marital status } & Cardiovascular & $9.1(31)$ & $11-20$ & $16.0(54)$ \\
\hline \multirow{2}{*}{ Unmarried } & 40.9 (139) & Eating disorders & $5.0(17)$ & $21-30$ & $1.8(6)$ \\
\hline & 501 (201) & Intensive care unit & $7.9(27)$ & \multicolumn{2}{|l|}{ Work sector } \\
\hline \multirow{2}{*}{\multicolumn{2}{|c|}{ Children }} & Gastrointestinal tract & $8.5(29)$ & Department of Health & $40.0(136)$ \\
\hline & \multirow{2}{*}{53.5 (182) } & Mental health & $2.1(7)$ & Private & $37.1(126)$ \\
\hline 0 & & Oncology & $3.2(11)$ & Education & $6.8(23)$ \\
\hline 1 & $17.4(59)$ & Paediatrics & $11.5(39)$ & Research & $3.5(12)$ \\
\hline 2 & $19.4(66)$ & Renal & $5.9(20)$ & Industry & $7.1(24)$ \\
\hline$\geq 3$ & \multirow[t]{2}{*}{$9.7(33)$} & Sports & $5.6(19)$ & Food service & $5.5(19)$ \\
\hline Language & & Other & $17.4(46)$ & \multicolumn{2}{|l|}{ Hours of work } \\
\hline Afrikaans & $50.3(171)$ & \multicolumn{2}{|l|}{ Years of practice } & Full-time & 72.6 (247) \\
\hline English & 37.9 (129) & $0-5$ & $45.3(154)$ & Part-time & $17.1(58)$ \\
\hline Indigenous & $11.8(40)$ & $6-10$ & $25.9(88)$ & Unemployed & $3.8(13)$ \\
\hline \multicolumn{2}{|l|}{ Residence } & $11-20$ & $18.8(64)$ & \multirow{2}{*}{$\begin{array}{l}\text { Not working as a } \\
\text { registered dietitian }\end{array}$} & \multirow{2}{*}{$6.5(22)$} \\
\hline South Africa & $93.2(317)$ & $21-30$ & $7.3(25)$ & & \\
\hline United Kingdom & $6.8(23)$ & $31-40$ & $2.7(9)$ & \multicolumn{2}{|l|}{ Contract } \\
\hline \multicolumn{2}{|l|}{ Location of work } & \multicolumn{2}{|l|}{ Salary } & Yes & $51.7(176)$ \\
\hline Urban/suburban & $83.5(284)$ & $<R 44999$ & $6.7(23)$ & No & $21.8(74)$ \\
\hline Rural or semirural & $16.5(56)$ & R45 000-R62 999 & $4.4(15)$ & Not applicable & $26.5(90)$ \\
\hline
\end{tabular}


an area of expertise in their dietetic practice. Diabetes $(16.8 \%, \mathrm{n}=$ $57)$ and paediatrics $(11.5 \%, \mathrm{n}=39)$ were most commonly specified as the field of expertise (Table I).

\section{Job satisfaction in relation to demographic variables}

Analysis of the demographic variables in relation to the level of job satisfaction identified age only as having a significant positive correlation (Spearman's $p$-value $=0.036$ ). Thus, as age increased, so did the overall level of job satisfaction. Those in the age group of 4049 indicated the greatest level of job satisfaction. As age advanced beyond 50 years, this level of satisfaction tapered downwards again. This older group, despite progressing towards retirement age, expressed frustration in their inability to proceed to higher positions than those currently held, independent of the sector of work within which they were currently employed. In comparison, although the younger generation of registered dietitians expressed a slightly higher level of job satisfaction than the oldest group, they reported being overworked and understaffed, having no autonomy and having to carry out monotonous work. They also reported poor use of their clinical skills, and they had an inability to gain expertise in an area of interest. According to the results of this study, the remaining demographic variables of gender, marital status, number of children, language and country of residence did not significantly impact on overall job satisfaction as reported by the registered dietitians.

\section{Job satisfaction in relation to the nine themes}

The overall job satisfaction score was found to be $65.7 \%$. This indicates that South African registered dietitians are slightly satisfied with their employment (Figure 1). When analysing the nine themes of job satisfaction using the adapted JSS, the overall results showed that registered dietitians were only slightly satisfied with opportunities for promotion (52.5\%) and the environment within which they worked $(61.3 \%)$, whereas they were moderately satisfied in relation to knowledge and skills $(68.7 \%)$, rewards of the work (68.3\%), colleagues [both dietetic (70.4\%) and nondietetic (71.2\%)], communication $(72.2 \%)$ and the nature of their work $(79.3 \%)$ Overall, the lowest level of satisfaction related to salary, slightly low

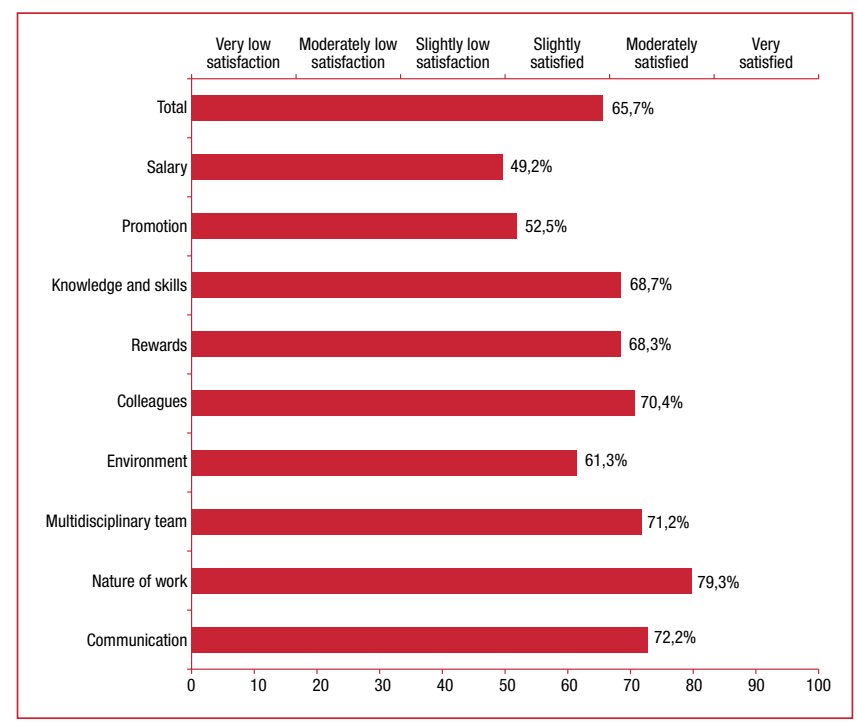

Figure 1: Job satisfaction scores per theme and overall scores for South African registered dietitians $(n=340)$ at $(49.2 \%)$. Although the overall results demonstrated a moderate level of satisfaction regarding communication and interaction within the multidisciplinary teams, many of the registered dietitians raised concerns about a general feeling of disrespect particularly from nurses, doctors and consultants. In contrast, the nature of the work scored the highest level of satisfaction. This suggests that registered dietitians are content with their career choice. If this were not the case, there would probably be a greater number of unemployed registered dietitians or dietitians leaving the profession. To some degree, this indicates that dietetic positions permit registered dietitians to fulfil what they were trained to do.

\section{Job satisfaction in relation to dietetic qualifications and expertise}

Significantly higher job satisfaction was reported by registered dietitians who had a reported area of clinical expertise (MannWhitney $\mathrm{U}$ test, $\mathrm{p}$-value $=0.001$ ) rather than by those who worked in general clinical practice. Interestingly, those who worked in the field of eating disorders (Mann-Whitney $U$ test, $p$-value $=0.013$ ), gastrointestinal diseases (Mann-Whitney $\mathrm{U}$ test, $\mathrm{p}$-value $=0.001$ ) and sports nutrition (Mann-Whitney $\mathrm{U}$ test, $\mathrm{p}$-value $=0.044$ ) were significantly more satisfied than dietitians who worked in other areas of expertise, or those without an area of expertise. Years in practice followed the same trend as age. Significantly higher job satisfaction was seen in registered dietitians who had been in practice for longer (Mann-Whitney U test, $\mathrm{p}$-value $=0.035$ ), than in those with fewer years of practice. Although level of education was not associated with a significant impact on job satisfaction (Kruskal-Wallis test, p-value $=0.12$ ), it is interesting to note that there was a marked increase in job satisfaction from master's to doctorate level. However, this difference was probably based in part on doctorate graduates being older and having a greater level of expertise. In this study, age and expertise independently demonstrated a positive influence on job satisfaction.

\section{Job satisfaction in relation to overseas-based registered dietitians}

When comparing the level of satisfaction of dietitians who worked in South Africa with those who worked in the UK (all international respondents were based in the UK), the overall level of satisfaction was reported to be slightly higher in the UK, although this difference was not significant (Mann-Whitney $U$ test, $p$-value $=0.291$ ). The only aspect of significant difference that was found between the two groups was based on salary (Mann-Whitney $U$ test, $p$-value $=0.01$ ). The UK-based registered dietitians were classified as moderately satisfied $(60.8 \%)$, whereas the South Africa-based registered dietitians were classified as having a slightly low level of satisfaction $(48.7 \%)$ with regard to their salaries.

\section{Job satisfaction in relation to current employment}

In the case of the respondents' current employment, significance pertaining to job satisfaction was found in relation to the hours of work (Kruskal-Wallis test, $p$-value $=0.021$ ), location of work, i.e. urban vs. rural (Mann-Whitney $U$ test, $p$-value $=0.00001$ ), and level of salary (Spearman's, $p$-value $=0.00001$ ). The majority of the respondents (72.6\%) was in full-time employment and was satisfied 
with their current positions vs. those who worked part-time or who were unemployed. In relation to work location, job satisfaction was found to be significantly greater in those who worked in urban areas than in those who worked in rural areas. The level of salary had a significant positive correlation with job satisfaction. This demonstrated that as the level of salary increased, so did the level of job satisfaction. The sector within which registered dietitians worked and had a contract seemed to secure a level of job satisfaction for registered dietitians. However, those who worked in industry and research showed higher levels of job satisfaction than those who worked in the other sectors.

\section{Forecast of dietitian movement in different job sectors in 2012}

To obtain a further indication of the level of job satisfaction, the dietitians were asked where they envisaged themselves in five years' time in relation to their current employment. The most movement by dietitians was predicted to occur in the $\mathrm{DOH}$ and in the food service management sectors: over $50 \%$ of currently employed dietitians in these two sectors claimed that, within the next five years, they would look for different jobs as registered dietitians (56\% and $58 \%$ respectively) (Figure 2). There was a a more stable work force in the research, industry and private sectors, where over $50 \%$ stated that they would remain in their current jobs $(60 \%, 55 \%$ and $54 \%$ respectively). In total, just over a third $(38 \%, n=129)$ of registered dietitians planned to stay in their current jobs. Almost two-thirds $(62 \%, n=211)$ intended to leave, showing a high employee turnover. The main reasons for employee turnover related to salary levels and opportunities for promotion. Thirty-five per cent of the dietitians (n $=119$ ) indicated that they would seek different dietetic posts. The remainder reported that they would emigrate, retire, or leave the profession altogether. An encouraging aspect of these data is that only $8 \%(n=27)$ of the registered dietitians pictured themselves seeking dietetic-based positions overseas. Fifteen per cent $(n=51)$ envisaged themselves leaving the profession altogether. This shows that there might be a loss of $20 \%$ of dietitians from the current dietetic workforce in South Africa. The high level of staff turnover should be a concern for employers, especially those based with the

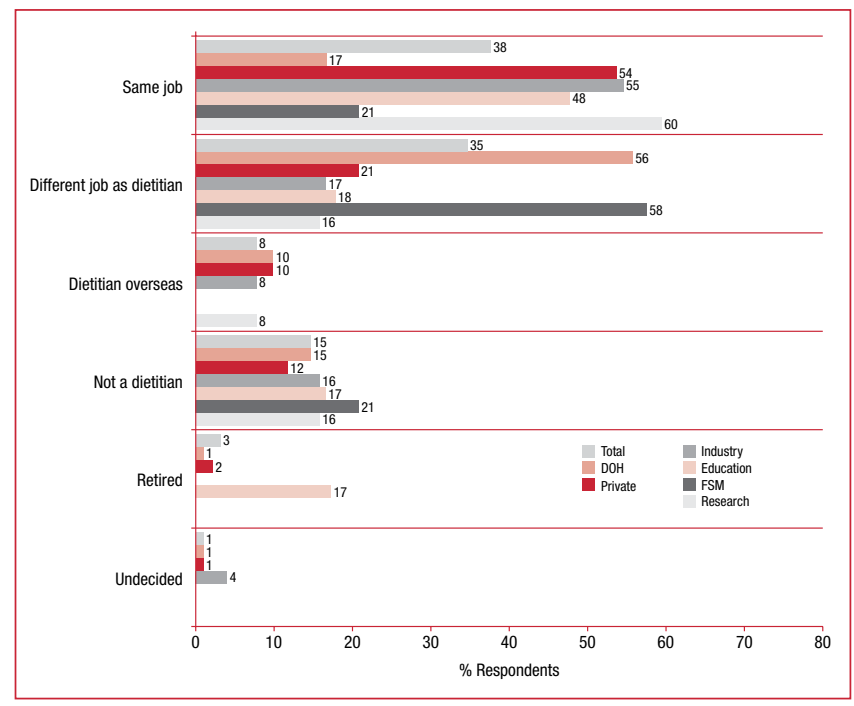

DOH: Department of Health, FSM: food service management

Figure 2: Forecast of registered dietitian movement in the different job sectors by 2012
$\mathrm{DOH}$, as approximately $83 \%(\mathrm{n}=113)$ of the current DOH dietetic workforce plan to search for alternative employment over the next five years (Figure 2).

\section{Discussion}

To our knowledge, this is the first study in South Africa that has investigated levels of job satisfaction among registered dietitians. The two methods of questionnaire distribution (e-mail and post) produced almost the same response rate. This study represented feedback that was received from just below one quarter of the dietetic workforce in South Africa. Reminder notices proved to be very valuable and substantially increased the response rate by almost one third. A representative sample of 340 responses (of 1509 dietitians) was obtained. The sample is regarded as representative because the sample size is sufficiently large enough to yield a precision of $5.45 \%$ when estimating a $95 \%$ confidence interval for an unknown proportion. It is also sufficiently large enough to test a hypothesis for a single proportion, where it is possible to detect a deviation of $8.8 \%$ from the hypothesised null-proportion with $90 \%$ power in a test with a significance level of $5 \%$. If a test for a single mean of any continuous variable was conducted, the sample size of 340 responses would also be sufficient to yield $90 \%$ power to detect an effect size of 0.176 in a test with a significance level of $5 \%$, regarded as a very small effect size.

For reasons previously explored, the researchers set out to undertake a postal and electronic survey and employed an acceptable methodology (used in a multitude of studies) to obtain the required information. Response rates in questionnaire-based studies vary greatly. ${ }^{21-32}$ The obtained response rate in this study is in line with that of other studies that employed the same methodology. Probable factors that contributed to the response rate included time of data collection (overlapping with part of the summer and school holidays), productivity in distribution and completion of the questionnaire via e-mail (possibly hampered by power shedding that South Africa was subjected to at the time of the study) and possible respondent fatigue (in general, healthcare professionals are inundated with many requests to partake in research).

The findings of this study showed that registered dietitians with the HPCSA were slightly satisfied (67.5\%) with their current position. This is lower than that reported by previous studies on job satisfaction among registered dietitians. ${ }^{5,43}$ The reported trend within previous American-based studies was of moderate job satisfaction. In 1989, the first study $(n=161)^{5}$ showed a satisfaction rate of $79.6 \%$ and in 2002 the second $(n=1321)^{44}$ showed one of $76.4 \%$. However, this study still confirmed that registered dietitians genuinely love the nature of their work and what they do, tending towards confirmation of career satisfaction. However, despite the differences, definite themes demonstrated differing levels of satisfaction in areas of the dietetic profession that require more attention.

\section{Expertise and experience}

In this study, it was found that the demographic variables of age, years of professional experience, and having an area of expertise significantly impacted on job satisfaction among the HPCSA registered dietitians. These three variables are interrelated. 
Professional experience increases with age and so does the likelihood of developing an area of professional expertise. This correlates with a recent Canadian study in which statistically significant relationships were found between years practised as a dietitian and personal accomplishment $(p$-value $=0.05)$ and age and personal accomplishment $(p$-value $=0.01) .^{45}$

Despite having carried out a year of compulsory community service in the $\mathrm{DOH}$ as part of their training programme, the younger dietitians either had high expectations once training was completed, or had not been sufficiently trained in practical skills outside the scope of dietetics. It is assumed that although the registered dietitians graduated with excellent nutrition and dietetic-related knowledge and skills, they might have lacked the necessary skills needed to achieve effective practice in the areas of business skills, administration, entrepreneurship and promotion of their profession, irrespective of the sector within which they were employed.

Apart from developing excellence in clinical and other practice, educational institutions that train registered dietitians in an undergraduate programme need to ensure that an adequate part of the training is dedicated to developing nondietetic skills that are required in practice (if not done so already). This would further support dietitians' skills in nutrition and dietetics. These skills, such as entrepreneurship and business ability, are recommended to ensure that dietitians become more business orientated. As well as acquiring learning skills outside the scope of dietetics, registered dietitians should challenge employers to allow them the opportunity to develop an area of expertise, where appropriate. It appears that this factor could play an important role in staff retention.

\section{Salary}

Salary levels were a major cause of reported low job satisfaction among registered dietitians working and living in South Africa. The trend was that those with higher levels of education, with the exception of those with doctorate degrees, experienced a lower level of job satisfaction. This trend was also apparent in other studies that were conducted on registered dietitians $s^{9,44,46}$ and other healthcare professionals, including occupational therapists, ${ }^{7,8}$ nurses ${ }^{23,25,47}$ and doctors. ${ }^{21,48,49}$ Registered dietitians, and especially those working in South Africa, did not feel that they were fairly paid, considering the time they had invested in their tertiary education to gain the knowledge and skills that they needed to carry out their jobs. Frustration was voiced that some employers, including government institutions and departments, did not acknowledge further study and postgraduate qualifications as being contributory to promotion and salary adjustments. A large proportion of those who had left the dietetic profession cited low salary levels, together with poor earning potential, as the main motivation for leaving the profession. A body of support is needed, in the re-evaluation of salary levels for registered dietitians in South Africa, so that salaries can be more comparable with those of similar professions regarding level of education and job responsibilities. This should also apply to medical aid schemes regarding promotion of the value of the registered dietitian as a means to greater cost-effective management of client profiles. Reevaluation of the value of a registered dietitian in patient care, and recognition that prevention (through the establishment of a healthy lifestyle) is better than cure, are needed. ADSA remains an excellent mouthpiece and is probably the best general "voice" for registered dietitians in South Africa. This group should continue to challenge medical aid schemes to promote the value of the registered dietitian, as well as the HPCSA, as it standardises the rates and fees of the dietetic professional body. Other societies, associations and interest groups that represent dietitians and the dietetic profession should also consider becoming involved with the bargaining process, within the scope of their mandates. Re-evaluation of salary levels should take levels of education, responsibilities and experience into consideration.

\section{Promotion and education}

Lack of opportunity for promotion was another strong reason for leaving the dietetic profession. Lack of promotion or progression stifles achievement and dampens job satisfaction. Lack of promotion opportunities was also cited in a study of Australian occupational therapists $(\mathrm{n}=113)^{8}$ and American occupational therapists $(\mathrm{n}=694) .^{50}$ In both countries, it was reported to be the main influencing factor that prompted occupational therapists to leave their profession. Strategies for dietitian-orientated career pathing need to be developed and should include a promotion or career ladder in graduated levels. Progression to different levels should encompass mounting levels of responsibility through increasing autonomy, and a reduction in monotony that would allow registered dietitians to openly and consistently re-evaluate the services they provide and to offer practical solutions in terms of service provision. Individual registered dietitians should be allowed to take the lead in more specialist services. These strategies could also be applied to private practice. This would encourage individuals to become innovative and opportunistic in their work.

Based on the findings of this study, an increase in education level does not appear to be a practical solution to improving job satisfaction levels at this stage, as employers currently do not necessarily acknowledge the furthering of education by increasing salary levels or creating promotion opportunities. This enforces the idea that often, further studies are are undertaken by individuals for personal achievement only, and in many cases without any external rewards. Based on the responses from the few respondents from the UK who worked for the National Health Service (NHS), this does not appear to be a trend that is unique to South Africa. Dietitians also reported that when working for the NHS, no recognition was afforded to further studies. Greger reported that no matter how highly qualified registered dietitians in the USA were, their salary levels did not change. ${ }^{51}$ Tertiary institutions, the dietetic need and registered dietitians need to challenge employers to develop a system that will facilitate academic recognition and the achievements of registered dietitians in the workplace.

\section{Staff retention}

Although the $\mathrm{DOH}$ was shown to be the most unstable sector for dietetic staff retention, this trend is not unique. All sectors within which registered dietitians were employed experienced a high level of staff turnover, and especially the education and food service management sectors. Industry and the research and the private 
sectors were only marginally more stable. Overall, a total of $62 \%$ registered dietitians planned to leave their current position within the next five years. This would be devastating in terms of the loss of expertise and experience, as well as the cost of staff replacement. It also places pressure on colleagues and possible loss in terms of continuity of therapeutic and patient care.

\section{Professional status or image}

The feeling of disrespect from nurses, doctors and consultants, as reported by registered dietitians, could result from one of three possibilities: a genuine disrespect or disregard for the profession by other professionals; the fact that dietitians are not assertive enough in their work; or because other professionals do not properly understand the benefit of nutritional intervention in patient health. From this, it seems that the status or image of registered dietitians needs to be improved among other healthcare professionals, especially doctors and nurses. This should be effected at undergraduate level and continue to those already economically active. Professional status should not be misunderstood or misperceived as registered dietitians wanting to boost personal or professional pride. It should rather be viewed as an element that would improve the multidisciplinary team's relationship in an effort to enhance dietetic activity and interaction. This would benefit procurement of maximal dietetic input on any given case. Media-based strategies are a method of increasing awareness and enhancing professional image. These should include advertising campaigns, regular nutrition-orientated television programmes, media articles that are written by registered dietitians, and even a monthly nutrition-based publication that is available at all newsagents. The promotion of professional image among fellow healthcare professionals is also proposed. This should start at undergraduate level by demonstrating the value of the registered dietitian in the multidisciplinary teams, in both academic and practical modules. This needs to be continuously re-enforced by integrating the work and research that are carried out by registered dietitians at study days and conferences hosted for fellow healthcare professional groups. However, registered dietitians will have to work hard to achieve the recognition that they deserve.

\section{Location of work}

Dietitians who worked in rural areas experienced significantly lower levels of job satisfaction than those who worked in urban areas. This is unsurprising, as on a global scale the literature demonstrates this among other healthcare professionals. ${ }^{36,48,49}$ The reasons for low job satisfaction were also very similar to those found in previous studies in which dietitians found it increasingly difficult to carry out their work effectively due to lack of resources, serious understaffing, professional isolation, limited budgets and a restriction on the development of an expertise because of dietetic posts that require generalist practice.

\section{Future studies}

Based on the findings of this study, more research needs to be carried out in terms of assessing job satisfaction among South African registered dietitians and registered dietitians on a global scale. Future studies within South Africa should include qualitative research and conduct open interviews with registered dietitians or focus groups to obtain more information regarding poor levels of job satisfaction. This could be further extrapolated to focus group discussions with other professionals to determine their attitudes towards registered dietitians and the dietetic role regarding patient care. Future studies should obtain input regarding possible solutions to the identified problems and possible avenues via which to effect positive change. Comparisons should be conducted on job satisfaction levels, or even attitudes towards salary levels and opportunities for promotion in other allied health professions that are registered in South Africa. This would help to determine whether similar trends occur in allied health professions, and if so, how this larger body of professionals could work together to challenge industry and governing bodies to improve job satisfaction levels. On a global scale, the methodology of this study could be extrapolated to determine the level of satisfaction in other countries, such as the USA, UK, Ireland, Australia, Singapore and New Zealand (due to the predominance of communication in English), to determine any similarities or differences in relation to the South African context. This task should identify areas of high satisfaction and further probe them to extrapolate their application to the South African context. An aspect or variable that was not considered in this study was the impact of job satisfaction of those in practice on the health outcome, nutritional status or even satisfaction with regard to dietetic service of the patients under dietetic supervision. This would be valid to determine to what extent job satisfaction influences and impacts on the productivity of the registered dietitian. After all, the main reason for assessing job satisfaction in the healthcare profession is to retain professionals and maintain service excellence to patients or clients.

\section{Conclusion}

In this study, South African registered dietitians experienced a lower level of job satisfaction than their American colleagues. The reasons for this were primarily found to be poor salaries, lack of promotion opportunities, lack of opportunities to develop an area of expertise and a perception of low professional image. On a positive note, this study still confirms that South African registered dietitians genuinely love the nature of their work and what they do, tending towards confirmation of career satisfaction. A forecast of the dietetic workforce over the next five years showed that areas of poor staff retention will occur in dietetic posts that are based in the public, educational and food service management sectors. Posts that are based in the private and industrial and research sectors will be marginally more stable. It is clear that the dietetic fraternity needs to proactively identify and explore avenues (including via professional boards and associations, societies and interest groups) to "take up the fight'" on the various issues relating to the dietetic profession that have been raised in this article. Recommendations to be investigated include re-evaluation of registered dietitian salary scales; career pathing, which should include promotion opportunities; and boosting the professional image of registered dietitians and enhancing dietetic undergraduate programmes by expanding the teaching of nondietetic skills, such as business skills and entrepreneurship, that are required to support dietetic practice on a broader scale.

\section{References}


1. Organ D. Organisational citizenship behaviour: the good soldier syndrome. Lexington, MA: Lexington Books; 1988.

2. Herzberg F. Work and the nature of man. New York: World Publishing; 1966.

3. Moeller NL, Fitzgerald MP. A meta-analysis of the relation to job characteristics to job satisfaction. Journal of Applied Psychology. 1985;70(2):280-289.

4. Syptak JM, Marsland DW, Ulmer D. Job satisfaction: putting theory into practice. Family Practice Management. 1999;6(9):26-30.

5. Rehn B, Stallings S, Wolman P, Cullen R. Job satisfaction of South Carolina dietitians. J Am Diet Assoc. 1989;89(7):979-981.

6. Dalton S, Gilbride JA, Russo L, Vergis L. Job satisfaction of clinical community and longterm care dietitians in New York City. J Am Diet Assoc.1993;93(2):184-188.

7. Moore $\mathrm{K}$, Cruikshank M, Haas M. Job satisfaction in occupational therapy: a qualitative investigation in urban Australia. Australian Association of Occupational Therapists. 2005;53:18-26.

8. Meade I, Brown G, Trevan-Hawke J. Female and male occupational therapists a comparison of job satisfaction. Australian Occupational Therapy Journal. 2005; $52: 136-148$.

9. Sullivan C, Leon J, Sehgal A. Job satisfaction among renal dietitians. J Ren Nutr 2006;16(4):337-340.

10. Mohr DC, Young GJ, Meterko M, et al. Job satisfaction of primary care team members and quality of care. Am J Med Qual. 2011;26(1):8-9.

11. Hellman CM. Job satisfaction and intent to leave. Journal of Social Psychology. 1997;137(6):677-689.

12. Collins $K$, Jones ML, McDonnell $A$, et al. Do new roles contribute to job satisfaction and retention of staff in nursing and professions allied to health? J Nurs Manag. 2000;8(1):3-12.

13. Delobelle $\mathrm{P}$, Rawlinson $\mathrm{JL}$, Ntuli $\mathrm{S}$, et al. Job satisfaction and turnover intent of primary healthcare nurses in rural South Africa: a questionnaire survey. J Adv Nurs. 2011;67(2):371-383.

14. Judge TA, Larson RJ. Dispositional affect and job satisfaction: a review and theoretica extension. Organizational Behaviour and Human Decision Processes. 2001;86(1):67-98.

15. Arvey RD, Bouchard TJ, Abraham LM. Job satisfaction: environmental and genetic components. Journal of Applied Psychology. 1989;74(2):187-192.

16. Van Saane N, Sluiter JK, Verbeek JHAM, Frings-Dresen MHW. Reliability and validity of instruments measuring job satisfaction: systematic review. Occup Med (London). 2003;53(3):191-200

17. King LA, Mclnerney PA. Hospital workplace experiences of registered nurses that have contributed to their resignation in the Durban metropolitan area. Curationis 2006;29(4):70-81.

18. Cortese C. Job satisfaction of Italian nurses: an exploratory study. J Nurs Manag 2007;15(3):303-312

19. Hall EJ. Nursing attrition and the work environment in South Africa health facilities Curationis. 2004;27(4):28-36

20. Buchbinder SB, Wilson M, Melick CF, Powe NR. Primary care physician and job satisfaction and turnover. Am J Manag Care. 2001;7(7):701-713.

21. Krogstad U, Hofoss D, Veenstra M, Hjortdahl P. Predictors of job satisfaction among doctors, nurses and auxiliaries in Norwegian hospitals: relevance for micro unit culture. Hum Resour Health. 2006;4:1-8.

22. Sveinsdottir H, Biering P, Ramel A. Occupational stress, job satisfaction and working environment among Icelandic nurses: a cross-sectional questionnaire survey. Int J Nurs Stud. 2006;43(7):875-190.

23. Lu H, While AE, Barriball L. Job satisfaction and its related factors: a questionnaire survey of hospital nurses in Mainland China. Int J Nurs Stud. 2007;44(4):574-588.

24. Li J, Lambert VA. Job satisfaction among intensive care nurses from the People's Republic of China. Int Nurs Rev. 2008;55(1):34-39.

25. Koorts AS, Marais AJ. A study of nurses of the RSA. Curationis. 1990;13(1/2):29-32.

26. Willem A, Buelens M, De Jonghe I. Impact of organisational structure on nurses' job satisfaction: a questionnaire survey. Int J Nurs Stud. 2007;44(6):1011-1020.

27. Thomas L, Valli A. Levels of occupation stress in doctors working in a South African public-sector hospital. S Afr Med J. 2006; 96(11):1162-1168.

28. Curtis EA. Job satisfaction: a survey of nurses in the Republic of Ireland. Int Nurs Rev. 2007;54(1):92-99.
29. Kekana HP, Du Rand EA, Van Wyk NC. Job satisfaction of registered nurses in a community hospital in the Limpopo province in South Africa. Curationis. 2007;30(2):24-35.

30. Grunfield E, Whelan TJ, Zitelsberger L, et al. Cancer workers in Ontario: prevalence of burnout, job stress and job satisfaction. CMAJ. 2000;163(2):166-169.

31. Hegney D, Plank A, Parker V. Extrinsic and intrinsic work values: their impact on job satisfaction in nursing. J Nurs Manag. 2006;14(4):271-281

32. Milisen K, Abraham I, Siebens K, et al. Work environment and workforce problems: a cross-sectional questionnaire survey of hospital nurses in Belgium. Int J Nurs Stud. 2006;43(6):745-754

33. Lu H, While AE, Barriball KL. Job satisfaction among nurses: a literature review. Int J Nurs Stud. 2005:42(3):211-227.

34. Jenkins M. The problems of recruitment: a local study. British Journal of Occupational Therapy. 1991;54(12):449-452

35. Painter J, Akroyd D, Wilson S. The predictive value of selected job rewards on occupational therapists' job satisfaction in ambulatory care settings. Occupational Therapy in Health Care. 1995;9(4):21-37.

36. Denham LA, Shaddock AJ. Recruitment and retention of rural allied health professionals in developmental disability services in New South Wales. Aust $J$ Rural Health. 2004;12(1):28-29

37. Akroyd D, Wilson S, Painter J, Figuers C. Intrinsic and extrinsic predictors of work satisfaction in ambulatory care and hospital settings. JAllied Health. 1994;23(3):155-164.

38. Agriesti-Johnston C, Broski D. Job satisfaction of dietitians in the United States. J Am Diet Assoc. 1982;81(5):555-559

39. Devine C, Jastran M, Bisogni C. On the front line: practice satisfaction and challenges experienced by dietetics and nutrition professionals working in community settings in New York State. J Am Diet Assoc. 2004;104(5):787-792.

40. Broski DC, Cook S. The job satisfaction of allied health professionals. J Allied Health. 1978;7(4):281-287.

41. Pratt $P$, Kwon J, Rew M. Perceived job importance and job performance satisfaction of selected clinical nutrition management responsibilities. J Am Diet Assoc. 2005;105(7):1128-1132

42. Reddout M. Perceptions of clinical dietetic practice: continuing education and standards. J Am Diet Assoc. 1991;91(8):926-930.

43. Spector PE. Measurement of human service staff satisfaction: development of the job satisfaction survey. Am J Community Psychol. 1985;13(6):691-713.

44. Mortensen JK, Nyland NK, Fullmer S, Eggett DL. Professional involvement is associated with increased job satisfaction among dietitians. J Am Diet Assoc. 2002;102(10):1452-1454.

45. Gingras J, De Jonghe LA, Purdy N. Prevalence of dietetic burnout. J Hum Nutr Diet. 2010;23(3):238-243

46. Whaley GA, Wright K. Male dietitians in 5 southern states: some perspectives on the profession. J Am Diet Assoc. 2000;100(12):1535-1537.

47. Bjork, IT, Samdal GB, Torstad S, Hamilton GA. Job satisfaction in a Norwegian population of nurses: a questionnaire study. Int J Nurs Stud. 2007:44(5):747-757.

48. Matsumoto M, Okayama M, Kajii E. Rural doctors' satisfaction in Japan: a nationwide study. Aust J Rural Health. 2004;12(2):40-48.

49. Koetzee T, Couper, ID. What interventions do South African doctors think will retain them in rural hospitals of the Limpopo province of South Africa? Rural Remote Health. 2006;6(3):581-586.

50. Bailey DM. Ways to retain or reactivate occupational therapists. Am J Occup Ther 1990;44(1):31-37.

51. Greger JL. Are additional degrees needed to support advanced medical dietetic therapy? Nutrition Today. 2007;42(4):194-197. 